Original Research Paper

\title{
Multi-Objective Optimization of FRP Jackets for Improving the Seismic Response of Reinforced Concrete Frames
}

\author{
${ }^{1}$ Corrado Chisari and ${ }^{2}$ Chiara Bedon \\ ${ }^{I}$ Department of Civil Engineering, University of Salerno, Fisciano (SA), Italy \\ ${ }^{2}$ Department of Engineering and Architecture, University of Trieste, Trieste, Italy
}

\begin{abstract}
In this study, a multi-objective Genetic Algorithm (GA) optimization procedure is proposed for the seismic retrofitting of Reinforced Concrete (RC) building frames via Fiber-Reinforced Polymer (FRP) jackets. The optimization problem is solved via numerically efficient but accurate Finite-Element (FE) models able to take into account the strengthening and ductility increase contribution for a given FRP jacketing configuration. Based on a reference RC frame case study, an optimization approach aimed to maximize the frame ductility and minimize the FRP volume/cost is proposed, by taking into account different FRP jackets thicknesses for the internal and external columns and well as for each separate frame floor. In doing so, careful consideration is paid also to the expected collapse mechanism for the frame and the approach to embed a further objective able to control the collapse mechanism into the procedure is described. The results show the potential of the approach, which not only provides the entire Pareto Front of the multi-objective optimization problem, but also allows for general considerations about the influence of the design variables on the response of a given $\mathrm{RC}$ building.
\end{abstract}

Keywords: Genetic Algorithms, Structural Optimization, Seismic Retrofitting, RC Frames, $q$-behavior Factor, Ductility, Collapse Mechanism

\section{Introduction and Research Objectives}

The use of Fiber-Reinforced Polymers (FRP) in civil engineering applications represents a well-established technique in current practice.

Examples can be found in the form of structural members for full space pultruded frames or hybrid footbridges (Gonilha et al., 2013; Yang et al., 2016; Mancusi et al., 2014), strips and grids for the retrofitting of masonry walls and arches (Martinelli et al., 2016; Gattulli et al., 2014; D'Ambrisi et al., 2013), structural joints (Panigrahi and Rashmi, 2016; Mishra et al., 2016; Ascione and Mancusi, 2012), rebars and aggregates (Yazdanbakhsh et al., 2016; Fava et al., 2016; Gattesco et al., 2015).

Further applications, as in the current research study, involve the use of FRP jackets for the seismic retrofitting of Reinforced Concrete (RC) structures. When FRP jackets are used for the confinement of RC columns, in particular, the enhancement in strength and ductility of the unreinforced columns can be so efficient that FRP jacketing represents one of the major retrofitting techniques for the improvement of the seismic performance of RC structures.
Due to this huge application of FRP jackets in practice, over the last years several researchers investigated the structural behavior of $\mathrm{RC}$ reinforced elements and assemblies, see for example (Balsamo et al., 2005; Duong et al., 2007; Reyes et al., 2010; Le-Trung et al., 2010; Parvin et al., 2010; Zhu et al., 2011; Alaedini et al., 2015).

Zou et al. (2007; Choi et al., 2014), optimization procedures have been also proposed for the enhancement of the seismic performance of retrofitted RC frames.

Zou et al. (2007) discussed the optimal performancebased design for FRP reinforced RC frames. Based also on a calculation example, in particular, they showed that the seismic response of a FRP-retrofitted RC frame can be efficiently optimized when the solution of the nonlinear pushover seismic drift design problem is given by the minimum thickness of the FRP jackets, hence by the minimum volume and material cost of the retrofitting technique. Assuming the thicknesses of the FRP jackets as the major design variables for the investigated RC frame, the optimization procedure was then solved by using the principle of virtual work and the Taylor series approximation. 
The cited work shows the advantages of the FRP application in terms of strength and ductility increment and claims that satisfactory improvement may be achieved for the collapse mechanism. However, this approach presents some drawbacks. Firstly, in order to have tractable analytical expressions for the objective function, simplified assumptions are to be considered, e.g., bilinear moment-rotation curve for the plastic hinges, supposed concentrated at the beam ends. No degradation in the hinge constitutive relationship is thus considered. Secondly, even though improvements in strength, ductility and collapse mechanism are observed, they are not made explicit in the optimization analysis, which is formulated simply as to minimize the FRP weight while satisfying interstorey drift code prescriptions.

In this study, it is shown that remarkable improvement in the formulation of the optimization problems may be achieved if a more general approach is taken into account. In particular, the Genetic Algorithm technique is used for the optimized design of FRP jackets. In doing so, the reference case study derived from (Zou et al., 2007) is considered and further investigated. The parametric numerical simulations are carried out in OpenSees (2009), via computationally efficient and refined Finite-Element (FE) models. The typical RC frame is modelled in the form of nonlinear force-based BeamColumn elements, in which the constitutive law at element level is evaluated by the fiber-approach applied to the cross-section. This assumption overcomes the limitations of bilinear concentrated plastic hinges.

The material model for the confined concrete members is then derived from (D'Amato et al., 2012). The advantage of this latter approach is that the material model is able to estimate the increment of strength and ductility due to the assigned FRP confinement. Furthermore, the model needs not to be changed in case of absence of FRP jackets. For the steel reinforcement, finally, the Giuffrè-Menegotto-Pinto model is used.

Two load distributions for the parametric pushover analyses are considered, i.e., with horizontal loads proportional to the building height (D1) and proportional to the seismic masses (D2) respectively. Through the optimization approach, for the RC frame case study, the thickness of the FRP wraps is assumed as a design variable, including different thicknesses for external and internal columns, as well as for each floor (i.e., 6 variables in total). The goals of the multiobjective optimization analysis are then given by (i) maximization of the $\mathrm{RC}$ frame ductility and (ii) minimization of the volume (hence the cost) of FRP jackets, by taking into account the current provisions of the seismic design standards in use for concrete structures (i.e., maximum inter-storey drift ratio (EN1998-1, 2004)). Careful consideration is given also to (iii) the expected collapse mechanism for the
$\mathrm{RC}$ frame, so that its seismic performance could be further optimized by means of global rather than local failure mechanisms.

As shown, interesting results are derived from the obtained multi-objective optimization solution. The main Genetic Algorithm optimization outcomes are then critically discussed, so that general design recommendations of technical interest could be derived.

\section{Structural Optimization Via Genetic Algorithms}

In the traditional approach, optimal design in structural engineering consists of finding the best structure according to $N$ pre-defined objectives $f_{i}, M$ equality constraints $g_{j}$ and $P$ inequality constraints $h_{k}$. In mathematical terms, this reads:

$$
\begin{array}{ll} 
& x=\operatorname{argminf}_{i}(x) i=1, \ldots, N \\
\text { s.t. } & g_{j}(x)=0 j=1, \ldots, M \\
& h_{k}(x)>0 \quad k=1, \ldots, P
\end{array}
$$

A maximization problem can be turned into a minimization one by simply changing the sign of the objective function. Restricting the attention on the monoobjective case for now, i.e., $N=1$, usually the primary objective to minimize is the cost of the structure and the constraints reproduce the structural requirements prescribed by the codes. Generally, the cost is assumed proportional to the weight of the structure (see, for instance, Sarma and Adeli, 1998), possibly scaling differently components made of different materials. In some cases, costs not directly dependent on the weight (i.e., due to transportation, welding, etc.) may be embedded in the procedure through specific terms in the cost function. Objectives and constraints depend on some input variables $x$ which are varied in the search for the solution. The space of the values that can be assumed by the input variables is called 'design space'.

Once the design space, the objective and the constraints are set, the solution of an optimization problem may be accomplished by using several different approaches. Basically, the cheapest methods in terms of computational burden (i.e., number of evaluations of the objective function) are those based on the evaluation of the gradient of the objective function (steepest descend, Box et al., 1969; trust region, Byrd et al., 1987). When the objective function is not explicitly known (as in the present case, where it results from the evaluation of FE model) and no information about the convexity of the function is present and, even more, in case of multiobjective optimization, less efficient but more general methods are preferred. Among those, Genetic Algorithms (GAs, Goldberg, 1989) are rather popular because of their ability to solve different typologies of problems. 


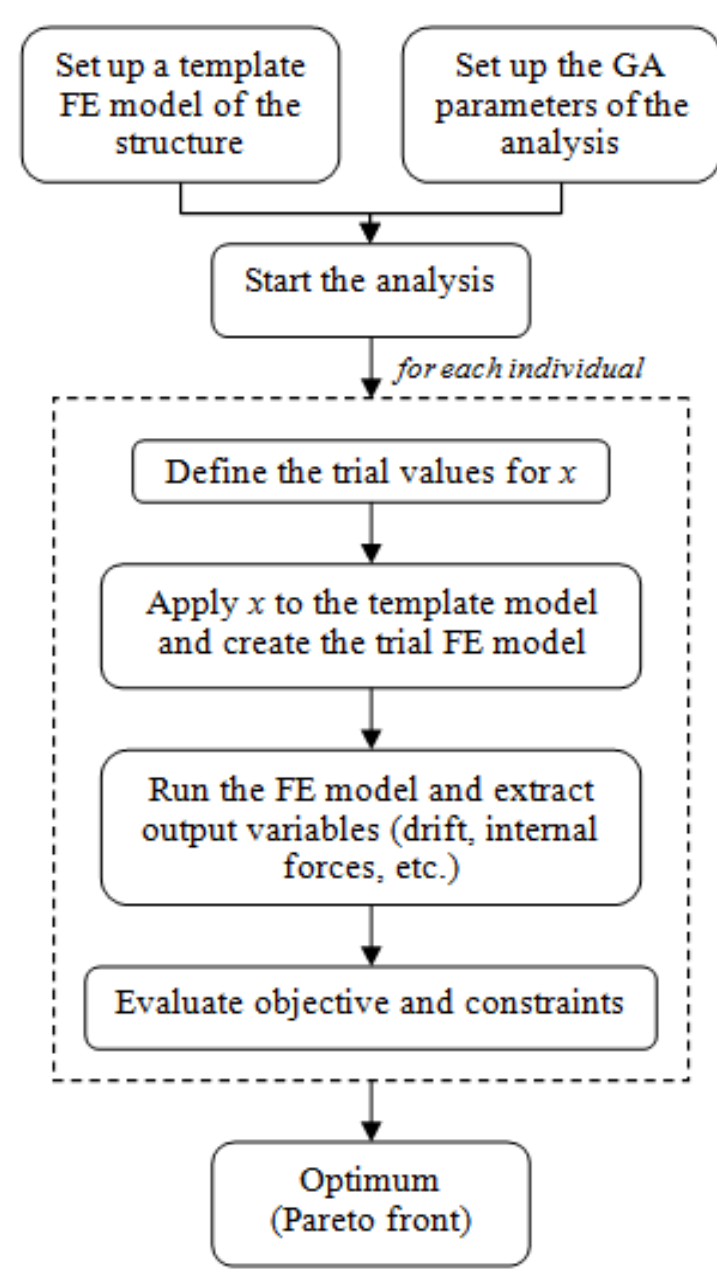

Fig. 1. Flowchart of the optimization process

GAs are a zero-order, population-based meta-heuristic widely used to solve difficult optimization problems. They mimic the optimum search as observed in nature, where living species evolve through recombination of their genetic pool. The algorithm starts with a population of randomly (or quasi-randomly) generated solutions. The chromosome of a solution (individual) is represented by the vector of the design variables $x$. The individuals in a population are then ranked based on their fitness, depending on the value assumed by the objective functions and an intermediate population is created by rearranging the previous one. High-fitness individuals may be duplicated and poor-performing individuals may disappear. Individuals in the intermediate population are selected to mate and, by recombination (crossover) of the parents' chromosomes, new individuals (offspring) are generated. These new individuals are the basis for the generation of a new population, which is evaluated after application of mutation with low probability (random changes in some genes) and elitism (best individuals of the parent population may remain in the new population). The new population is in average better than the previous and after evaluation undergoes the same operators described, i.e., ranking, selection, crossover, mutation, elitism. The iterative process is stopped when some condition is met. In the problems described in this study, the termination condition consisted of a fixed number of generations.

The general scheme which must be followed when a structural optimization problem is approached by means of GAs is outlined in Fig. 1. After defining a template FE model and setting up the GA parameters, the analysis, which applies the concepts briefly described above, consists of evaluating the individuals within each generation, i.e., running each FE model represented by the individual, extracting output variables (interstorey drift, internal forces, displacements) and evaluating objectives and constraints. In the following section, objectives and constraints for the general case of the optimal design of retrofitting for RC frames by means of FRP jackets will be described.

\section{Design Methods and Objectives}

\section{Multi-Objective Optimization Strategy}

When applied to seismic retrofitting, the approach described in the previous section is particularly effective. Depending on the specific aim of the retrofitting action, different objectives may be selected. As an example, Poh'sie et al. (2016) designed a Tuned Mass Damper system according to different objectives related to the response under ground motion of the structure equipped with the device, i.e., minimizing the peak acceleration/displacement or the average of the higher acceleration or displacement. This implied evaluating the dynamic response under several ground motions and working on appropriate statistics of the single responses.

When applying the Genetic Algorithm optimization approach to RC structures retrofitted with FRP jackets, the approach itself must be modified to properly take into account the intrinsic features, advantages and limits of the retrofitting technique, as well as the set of structural design requirements that the main structural system should in any case guarantee under seismic loading conditions, in accordance with the actual design standards (EN1998-1, 2004).

Based on past research (i.e., Teng et al., 2002; Braga et al., 2006), it is in fact well-known that the main effect of FRP jackets turns out to be increasing ductility and strength of the members for a given structure, due to their confinement contribution. On the contrary, no effect is usually encountered on the stiffness and mass of the same structure and thus on its modal characteristics. From this point of view, to maximize the effectiveness of the FRP reinforcement, the design should be based on the response under push-over analysis, which is simpler 
to perform compared to nonlinear dynamic analysis and provides a clear picture of the post-elastic behavior of the structure.

Even though the cost (herein assumed as proportional to the total weight of the FRP wraps) is clearly one of the design variables to minimize, a practitioner could wish to design the seismic retrofit maximizing the effect at a larger cost. Furthermore, in the applicative example it will be shown that another interesting objective could be formulated as to control the collapse mechanism of the overall structure. These requirements naturally lead to a multi-objective optimization problem, where more than one conflicting objectives are to be optimized. In the context of multi-objective optimization, the concept of Pareto optimality replaces the usual notion of optimality (Miettinen, 1999). In a minimization problem with $N$ objectives, a solution $x_{1}$ is said to dominate a solution $x_{2}$ if and only if:

$$
\begin{array}{ll}
f_{i}\left(x_{1}\right) \leq f_{i}\left(x_{2}\right) & \forall i=1, \ldots, N \\
f_{j}\left(x_{1}\right)<f_{j}\left(x_{2}\right) & \exists j=1, \ldots, N
\end{array}
$$

where, $f_{i}$ is the $i$-th objective to minimize. A solution is referred to as Pareto optimal if it is not dominated by any other solution. The set of Pareto optimal solutions, called Pareto Front (PF), represents the general solution of the problem. Most methods for solving multi-objective optimization problems, such as the Weighted Sum Method (Stadler, 1979), convert them into simpler problems, in which a scalar function of the objectives is minimized or maximized. Under some assumptions, this approach gives a solution belonging to $\mathrm{PF}$ and representative of an acceptable compromise between all the (possibly conflicting) objectives. The main trouble of the strategy is that the definition of 'acceptable compromise' is left to the user, who should carefully define the objective weights a priori. On the contrary, within the context of Genetic Algorithms, the main advantage is that the whole Pareto Front can be fully tracked without setting a priori the weight to assign to each objective. The choice of a unique solution-if needed by the user-can be consequently postponed.

\section{Seismic Design Prescriptions (Constraints)}

Through the current FE parametric study, the retrofitting optimization was carried out by taking into account the main provisions that the Eurocode 8 (EN1998-1, 2004) gives for the seismic design of RC building frames.

In that respect, in particular, the push-over analyses were performed by comparing the $\mathrm{RC}$ frames performances at two limit states, i.e., the Damage Limit State (DLS) and the Near Collapse Limit State (NCLS) configurations.
In the first case, the DLS maximum drift of a given $\mathrm{RC}$ frame was properly limited, so that the limit value $0.005 h$, with $h$ the inter-story height, would not be exceeded. In terms of Near Collapse Limit State, a 20\% drop of lateral resistance of the structure was considered, as generally accepted in practice.

\section{Material Model}

Through the optimization study, the parametric FE simulations were carried out via advanced, numerically efficient but accurate numerical models able to properly take into account the FRP-jacketing effects on the overall seismic performance of a given $\mathrm{RC}$ frame. It is well known that given a RC member, transverse reinforcements in general, such as steel stirrups, internal ties and/or fiber-reinforced polymer FRP jackets, produce a confinement action which opposes the expansion of the concrete core, thus causing a state of triaxial stress inside the element. From a qualitative point of view, the stress-strain relationship characterizing the concrete behavior for an unconfined or confined member can be in fact assumed according to Fig. 1 .

In the current study, a key role was hence assigned to the numerical implementation of the FRP mechanical properties for all the RC members. The modelling approach proposed in (D'Amato et al., 2012), based on the earlier confinement theory of (Braga et al., 2006) for the calculation of the confining pressure acting in the section core of a FRP reinforced concrete member, was taken into account. The advantage of the assumed approach is that the material model is able to estimate the increment of strength and ductility due to the assigned FRP confinement for a given RC member (Fig. 2). A further potentiality is that the model can incorporate a wide set of confinement configurations, hence resulting in a versatile tool. Compared to (Braga et al., 2009), in addition, the latter model accounts also for the tensile strength of plain concrete and was specifically developed to evaluate the cyclic non-linear response of RC structures with degraded linear unloading/reloading stiffness.

Basically, given a RC section, OpenSees builds and stores the confined concrete envelope curve by performing an incremental and an iterative procedure. The reader is referred to (D'Amato et al., 2012) for the full description and validation of the material model. The computed confined stress-strain relationships are then utilized in the non-linear structural analysis of the given system under the assigned design loads.

\section{Case Study}

\section{Geometry and Materials}

As a reference case study, the 3-storey, 3-bay RC frame investigated in (Zou et al., 2007) was taken into 
account, Fig. 3. The reference frame is considered as part of an office building, supposed to be located in an intensity I seismic zone of Italy, in accordance with the Eurocode 8 (EN1998-1, 2004).

A $250 \times 600 \mathrm{~mm}$ cross-section was considered for all the beams. The external columns, at the same time, consisted of $300 \mathrm{~mm}$ dimension square columns, while for the internal columns a $400 \mathrm{~mm}$ dimension cross-section was taken into account. The details of the reinforcement for the $\mathrm{RC}$ frame elements are shown in Fig. 4.

In terms of mechanical calibration of materials, concrete was assumed to have an unconfined compressive strength equal to $f_{c}=21 \mathrm{MPa}$. According to the formulation proposed by the Model Code (2012), the corresponding Young modulus was set equal to $E_{c}=30660 \mathrm{MPa}$, while the ultimate strain for confined concrete was assumed as $\varepsilon_{2}=0.0356$. The steel reinforcement was then characterized by Young modulus $E_{s}=210 \mathrm{GPa}$, yielding stress $f_{y}=300 \mathrm{MPa}$, strain-hardening ratio 0.01 and ultimate strain equal to $3 \%$. Finally, the FRP reinforcement was considered in the form of an elasticbrittle material, with Young modulus $E_{f}=230 \mathrm{GPa}$ and ultimate strain $\varepsilon_{f, u}=0.00913$, corresponding to an ultimate stress $\sigma_{f, u}=2100 \mathrm{MPa}$. This latter value represents the FRP hoop strength, significantly lower than the flat coupon strength obtained in tensile tests.

\section{Finite-Element Modelling}

The typical RC frame was modelled in OpenSees (2009). All the frame members were represented by nonlinear force-based Beam Column elements, in which the constitutive law at element level is evaluated by the fiber-approach applied to the cross-section. The material model utilized for the confined concrete was calibrated based on the description provided in the "Material model" section and primarily characterized by the capability to estimate the increment of strength and ductility due to the FRP confinement. The model needs not to be changed in case of absence of FRP jacket. The material model for the steel reinforcement was the Giuffrè-Menegotto-Pinto model.

Through the FE investigation, the columns were fixed at the base. A first loading step accounting for the gravity load was considered, before performing the pushover analyses. The gravity loads consisted of the self-weight plus a distributed loads equal to $p=50 \mathrm{kN} / \mathrm{m}$ on the beams. In the following step, two load distributions for push-over analyses were considered, the first (D1) with horizontal loads increasing proportionally to the building height and the second (D2) with horizontal loads proportional to the seismic masses. The total mass of the RC frame was estimated to be equal to $285.86 \mathrm{t}$, as given by the concrete density $\gamma=2300 \mathrm{~kg} / \mathrm{m}^{3}$ plus the distributed loads applied on the beams. Finally, $P-\Delta$ effects were not taken into account.

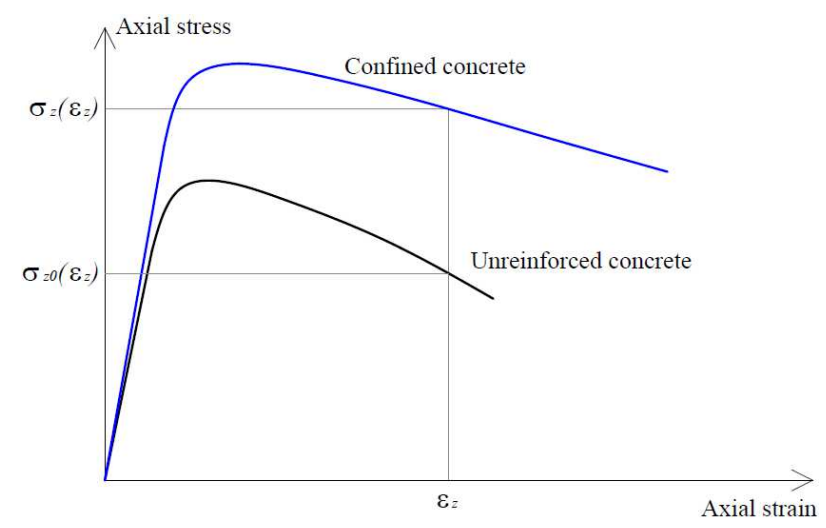

Fig. 2. Strength increase effect for a $\mathrm{RC}$ member with confinement, in accordance with (D'Amato et al., 2012)

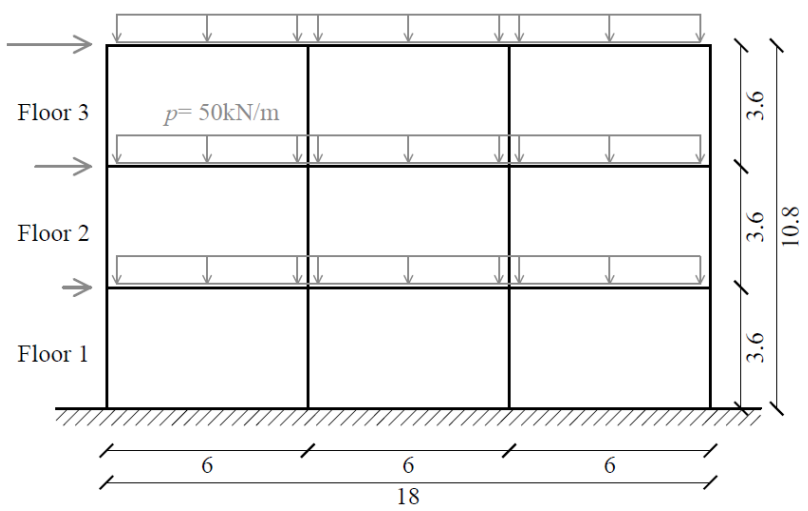

Fig. 3. Reference geometry for the RC frame object of investigation. Nominal dimensions in meters

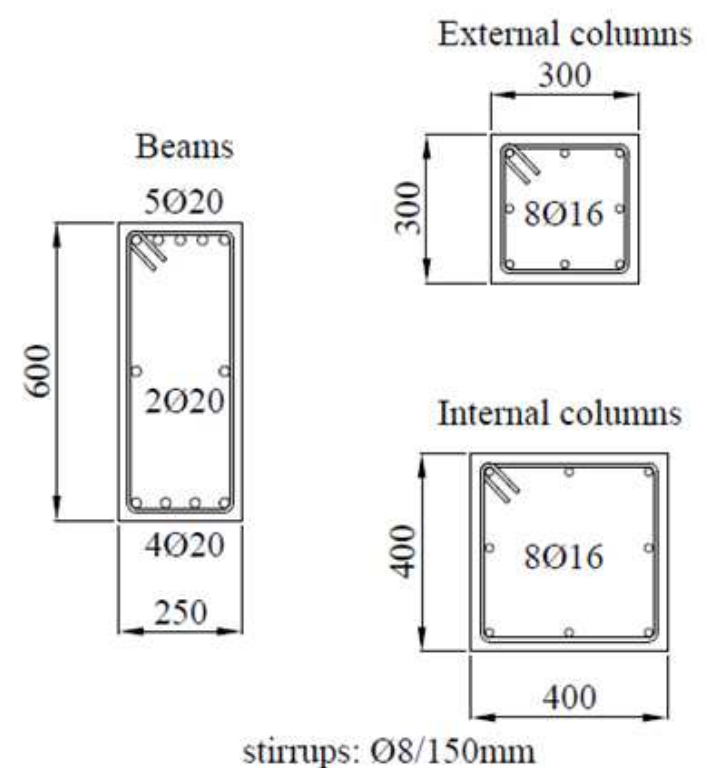

Fig. 4. Cross-section properties for the concrete structural elements. Nominal dimensions in millimeters 


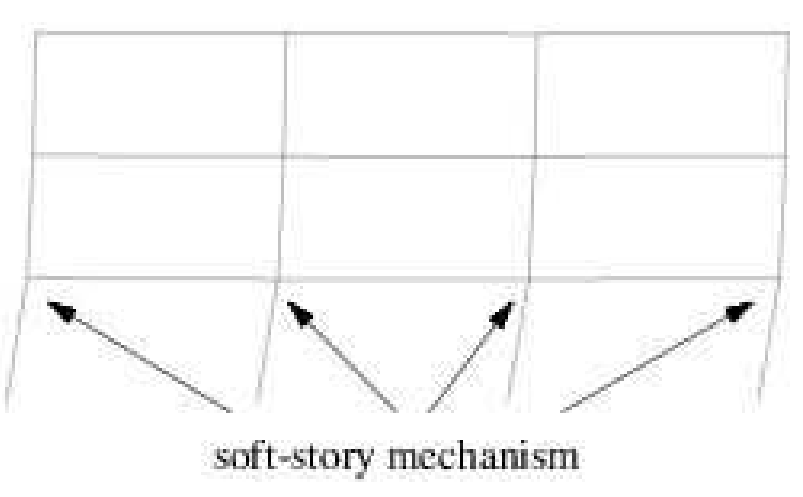

Fig. 5. Deformed shape of the bare RC frame, with evidence of the soft-story mechanism

\section{Preliminary Finite-Element Model Validation}

A first modal analysis of the bare frame was performed. The numerically predicted fundamental period of vibration $T_{1}$ for the unreinforced RC frame resulted equal to $0.798 \mathrm{sec}$.

Based on the $T_{1}$ reference value, the DLS design base shear-according to the Eurocode 8 (EN1998-1, 2004) elastic spectrum-was evaluated as $V_{e, D L S}=$ $782 \mathrm{kN}$. For each reference FE model, the so calculated value was then properly scaled, based on the $q$-behavior factor derived from the capacity curve of the reinforced structure.

At a preliminary stage of the research project, a further validation of the FE modelling assumptions was also carried out by taking into account the seismic performance of the reference unreinforced $\mathrm{RC}$ frame, as described in (Zou et al., 2007). In this regard, it must be pointed out that, although the same RC frame of (Zou et al., 2007) was considered in the current work, totally different FE modelling assumptions were taken into account, thus the comparison between the respective FE results should be seen as qualitative only. In particular, no details about steel reinforcement are described in (Zou et al., 2007), except for a reinforcement ratio, which is only matched approximately by the layout depicted in Fig. 4. Furthermore, unlike the approach described above, beams and columns in (Zou et al., 2007) were considered as fully elastic, with plastic hinges at the end nodes only. The constitutive law of this hinges was obtained by analytically integrating Lam and Teng (2003) model for FRP-confined concrete over the cross-section and over the hinge length.

In general, a good agreement was found in terms of initial stiffness and maximum base shear for the two FE modelling assumption, both in the case of the bare frame and the FRP-retrofitted one.
The deformed shape of the examined RC frame without FRP-reinforcement is proposed in Fig. 5, as obtained at collapse under the effects of the D1 loading configuration. It is clear, as shown, that the collapse involves a pure soft-story mechanism, with formation of plastic hinges at the ends of the ground floor columns.

\section{Optimization Analyses}

Based on the preliminary FE validation, multiobjective optimization analyses were then conducted according the scheme described in the previous sections (i.e., Fig. 1). A Genetic Algorithm with the following properties was used:

- Initial population creation: Sobol sequence

- Population size: 50 individuals

- Number of generations: 50

- Ranking type: Linear, with scaling pressure 2.0

- Selection type: Stochastic Universal Sampling

- Crossover type: BLX- $\alpha$, with probability 1.0 and parameter $\alpha=2.0$

- Mutation type: Aleatory, with probability 0.007

Each one of the listed parameters was set based on previous research in optimization problems (Chisari et al., 2015a; 2015b). The Genetic Algorithm was implemented in the software TOSCA (Chisari, 2015).

As design variable of the optimization problem, the thickness of the FRP wraps applied to the columns was considered. In particular, different thicknesses were assumed for external and internal columns and for each floor. The problem consisted thus of six design variables (three floors times two column typologies). The FRP thicknesses were allowed to vary between 0 (no reinforcement) to $2 \mathrm{~mm}$, with $0.001 \mathrm{~mm}$ increments.

Once the trial values for the design variables were set for a generic individual of any population, a FE model of the reinforced structure was created and a push-over analysis performed. From the results of the pushover analysis the following quantities were then extracted:

- Capacity curve of the RC frame, i.e., in the form of base shear-top displacement

- Inter-storey drift at each imposed load (displacement) increment

- Maximum steel strain in each RC member, at each imposed load (displacement) increment

From this amount of information, several key values were thus evaluated, including: 
- The first yielding point $\left(F_{y}, u_{y}\right)$, i.e., the time step in which the first yielding in steel occurs (i.e., for any structural element belonging to the whole structural system)

- The peak load point $\left(F_{\max }, u_{\max }\right)$, as obtained in terms of base shear and top displacement

- The ultimate state point $\left(F_{u}, u_{u}\right)$, defined as the point after the peak load point where either a $20 \%$ drop of the peak base shear occurred or where the analysis did not converge anymore due to achievement of the ultimate strain in the concrete (and thus rotation capacity of the section)

Finally, the following quantities were calculated:

- Ductility: $\mu=\frac{u_{u}}{u_{y}}$

- $q$-behavior factor: $q=\frac{F_{y}}{u_{y}} \frac{u_{u}}{F_{\max }}$

- $\quad$ DLS design base shear: $V_{d, D L S}=\frac{V_{e, D L S}}{q}$

- $\quad$ DLS inter-storey drift ratio: $d_{D L S}=d\left(V_{d, D L S}\right)$

As previously discussed, the objectives of the multiobjective optimization analysis were set as the maximization of $\mu$ and the minimization of the volume of FRP, with the reference constraint that $d_{D L S} \leq 0.005$.

For each FE model, two different optimization analyses were carried out depending on the horizontal load distributions, i.e., a first-mode proportional distribution (D1) and a mass-proportional distribution over the frame height (D2).

\section{Discussion of FE Results}

Given the proposed optimization problem, the Pareto Front represents the threshold between the conflicting objectives of increasing ductility and limiting cost (FRP volume). The Pareto Fronts obtained from the current research investigation - for both the D1 and D2 loading conditions - are displayed in Fig. 6.

Looking at Fig. 7, some important suggestions can be derived. It is in fact clear that while for low levels of FRP volume-ductility the relationship between them is almost linear, the increase of ductility degrades as the cost increases. In other words, after a certain point, the advantages in terms of ductility are negligible, compared to the cost increase. This happens for both D1 and D2 force distributions.

Another interesting point emphasized by Fig. 6 is that for the same value of cost, the ductility of the system under D1 horizontal forces is greater, meaning that the structure responds better to this distribution. Thus, for the RC frame object of investigation, a design based on forces proportional to the seismic masses (D2) is recommended since conservative.

A more detailed analysis of the obtained results was then performed. In Fig. 7, for example, the $\mu$ values of individuals in the Pareto Fronts are plotted against the thickness of FRP wraps at the base floor ('Floor 1') of the $\mathrm{RC}$ frame, for the external and internal columns respectively. As the analysis tries to keep cost (and thus wrap thickness) as low as possible, from these plots it is possible to infer the relative importance of the variables themselves on the objectives. In Fig. 7 it can be in fact seen that there is strong correlation between ductility and FRP thickness at the first floor for the internal columns, as the former increases almost linearly with the latter. Conversely, the algorithm keeps thickness in the external columns as low as possible in the same range of ductility. When the thickness in the internal columns reaches the maximum allowed value ( $2 \mathrm{~mm}$, in this investigation), there is still room for improvement in ductility, at expenses of great increase in thickness of FRP applied at the external columns only (Fig. 7, 'Floor 1').

On the contrary, the reinforcement at the other building floors is remarkably less important in terms of global response of the frame, as it can be seen in Fig. 7, 'Floor 2' and 'Floor 3' charts. Because of its negligible effects on the ductility increase and substantial contribution in the total cost, the FRP thickness is consequently kept as low as possible.

The optimal FRP thicknesses are finally reported in Table 1, as obtained from the full optimization study. It is clear that even though some of the proposed design thicknesses are not zero at the second and third floor, they are 2 or 3 order of magnitude less than the maximum thickness and should consequently be fully neglected from a numerical point of view.

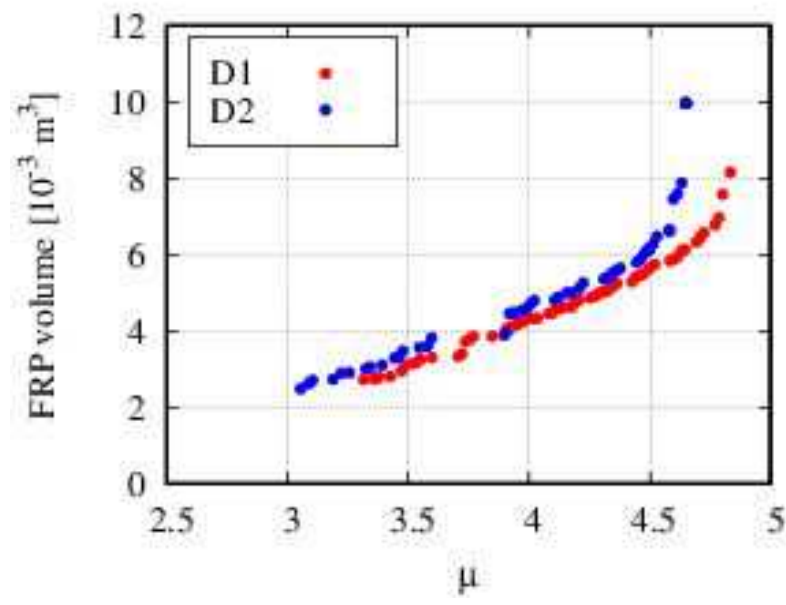

Fig. 6. Pareto fronts of the optimization analyses, as obtained for the D1 and D2 loading conditions respectively 

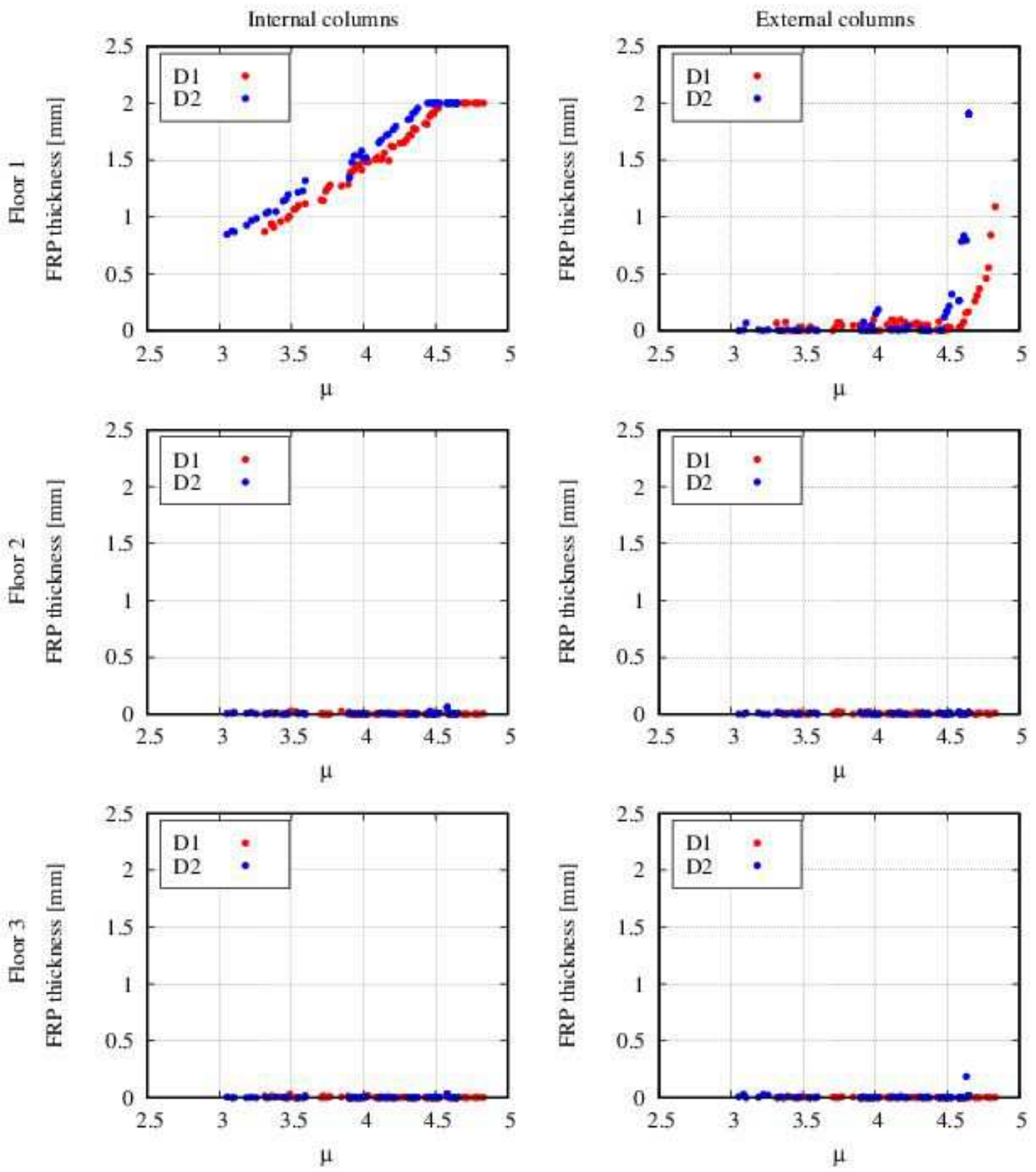

Fig. 7. Dependence of ductility on FRP wrap thickness, as obtained for internal/external columns at each floor

Table 1. Optimal solutions, divided by frame floor, column type and loading condition

\begin{tabular}{|c|c|c|c|c|c|}
\hline \multirow{3}{*}{ Story } & \multirow{3}{*}{ Column type } & \multicolumn{4}{|c|}{ Thickness [mm] } \\
\hline & & \multicolumn{2}{|c|}{ Ductility optimal } & \multicolumn{2}{|c|}{ Cost optimal } \\
\hline & & D1 & D2 & D1 & D2 \\
\hline \multirow[t]{2}{*}{1} & External & 1.090 & 1.906 & 0.066 & 0.000 \\
\hline & Internal & 2.000 & 2.000 & 0.870 & 0.846 \\
\hline \multirow[t]{2}{*}{2} & External & 0.010 & 0.013 & 0.016 & 0.001 \\
\hline & Internal & 0.005 & 0.006 & 0.000 & 0.005 \\
\hline \multirow[t]{2}{*}{3} & External & 0.002 & 0.016 & 0.001 & 0.008 \\
\hline & Internal & 0.001 & 0.003 & 0.014 & 0.005 \\
\hline
\end{tabular}

\section{Collapse Mechanism Control}

An additional optimization study was finally carried out by taking into account the collapse mechanism for all the examined building configurations. In Fig. 5, it was in fact shown that the collapse mechanism of the bare frame is controlled by the formation of plastic hinges at the ends of the first floor columns only. It is well-known, in this context, that this type of collapse mechanism, called soft-story mechanism, is undesirable because it leads to minimal energy dissipation. The aim of the additional 
investigation summarized in this subsection was thus to verify if in the framework of an optimized design it is possible to control the building collapse mechanism.

To do so, the analysis of all the frames under the D2 load distribution only was repeated, by taking into account a new objective $f_{\text {mech }}$ able to control the collapse mechanism of each frame.

Given the increase in the number of objectives, compared to the previous optimization study, the number of generations was set equal to 100 . The additional objective was then defined as:

$$
f_{\text {mech }}=\left\{\left(\frac{d_{1}}{d_{2}}-1\right)^{2}+\left(\frac{d_{2}}{d_{3}}-1\right)^{2}+\left(\frac{d_{3}}{d_{1}}-1\right)^{2}\right\}
$$

where, $d_{i}, i=1, . .3$, is the $i$-th inter-storey drift ratio evaluated at the NCLS state for each frame. Minimizing Equation 3 means enforcing the same inter-storey drift ratio among the floors at the NCLS state, hence providing a global mechanism for the examined RC structure.

Figure 8 shows the ductility- $f_{\text {mech }}$ scatter plot for the Pareto Front individuals, as obtained from such analysis. It is clear that a strong correlation exists between the two variables and the system approaches the global mechanism only for low levels of ductility.

In Table 2, the NCLS inter-story drift for the bare frame, the minimum $f_{\text {mech }}$ and the maximum $f_{\text {mech }}$ individuals are reported. It should be noted that even though the bare frame seems to behave better than the others, as far as the ratio between inter-story drifts is considered for comparisons, the same bare frame undertakes a maximum drift ratio $d_{D L S}=0.0136>0.005$, hence it does not comply to the DLS prescription taken into account through the optimization problem (EN19981, 2004). Conversely, all the Pareto Front individuals displayed in Fig. 8 satisfy this constraint.

From the results collected in Fig. 8 and Table 2, the correlation between ductility and $f_{\text {mech }}$ becomes clear, as it is evident that when higher ductility is encountered, this effect strictly depends on the increase of the interstory drift at the first floor, while the other floors show almost constant horizontal displacements. This aspect results in higher $f_{\text {mech }}$ values.

Based on the collected FE results it is also reasonable to state that, for the investigated $\mathrm{RC}$ frame, the improvement in the mechanical properties of the RC members - as achieved by means of FRP jacketing - is not sufficient to modify considerably the collapse mechanism of the unreinforced RC structure, i.e., leading from soft-story to global collapse phenomena. It is expected, however, that the proposed approach could be effective when design variables allowing for greater modifications in the global behavior of a given structural system could be taken into account.

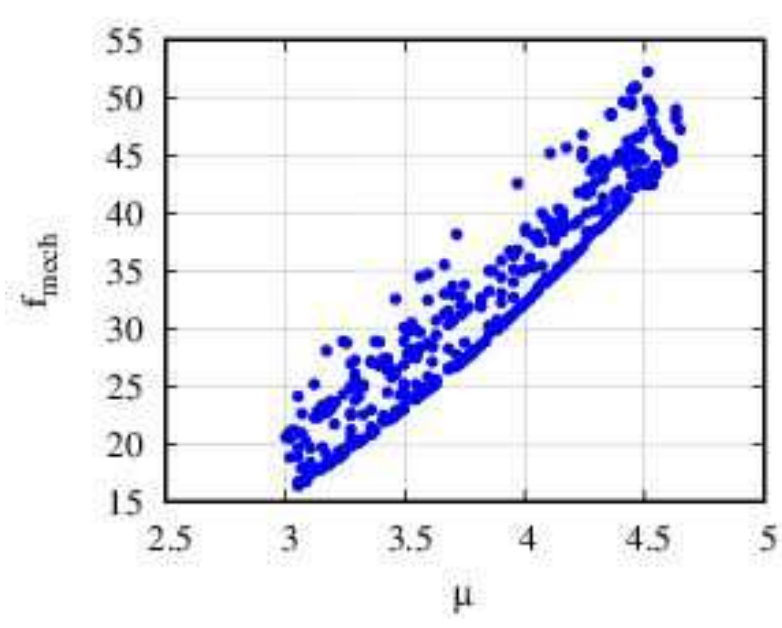

Fig. 8. Dependence of mechanism control objective on ductility for the Pareto Front individuals

Table 2. Inter-storey drift ratios at each frame floor, as obtained in the optimization analysis accounting for the collapse mechanism

\begin{tabular}{llll}
\hline & Interstorey drift ratio $[\%]$ & \\
Floor & Bare frame & Minimum $f_{\text {mech }}$ & Maximum $f_{\text {mech }}$ \\
\hline 1 & 1.12 & 2.07 & 3.38 \\
2 & 0.43 & 0.44 & 0.42 \\
3 & 0.20 & 0.19 & 0.19 \\
\hline
\end{tabular}

\section{Conclusion}

In this study, a Genetic Algorithm optimization procedure has been proposed for the seismic retrofitting of $\mathrm{RC}$ building frames via FiberReinforced Polymer (FRP) jackets.

Through the optimization approach, the thickness of the FRP jackets was set as main design variable, including the option that different FRP thicknesses were allowed for internal/external columns as well as at each frame floor. The optimal solutions were derived from push-over analyses carried out by imposing separately two load distribution, i.e., a first-mode proportional distribution and a mass proportional one respectively. The design constraints were then detected on the base of the current seismic standard provisions. In the first analyses, the objectives of minimizing overall cost and maximizing ductility while satisfying code prescriptions about inter-story drift.

The obtained results highlighted that the considered optimization approach is able to detect the parameters to which the structural response is more sensitive. For the RC frame considered as case study, in particular, strengthening the first floor internal columns resulted the solution able to lead to the best compromise between ductility increase and minimum retrofitting cost. In the study, it was also shown that the assumption of multiple optimization objectives, i.e., including for example an 
objective related to the expected collapse mechanism, can be easily implemented in the procedure. For the examined frame, it was shown for example that the softstory mechanism of the original frame, designed with strong beams and relatively weak columns, cannot be modified as to resort to a global mechanism by simply adding FRP jacketing to the unreinforced system. In general, however, the proposed approach is expected to be effective when design variables allowing for greater modifications in the global behavior of a given structural system can be taken into account. This will be explored is future research.

\section{Author's Contributions}

Corrado Chisari: Finite-Element numerical modelling, FE model validation, Genetic Algorithm optimization, FE data interpretation, paper writing and critical review of its scientific content.

Chiara Bedon: FE model validation, FE data interpretation, paper writing and critical review of its scientific content.

\section{Ethics}

The authors declare that this article is original and contains unpublished material only. The corresponding author also confirms that both the authors have read and approved the manuscript and no ethical issues are involved.

\section{References}

Alaedini, S., M.Z. Kabir and H. Hejabi, 2015. Seismic ductility evaluation of shear-deficient RC frames strengthened by externally bonded CFRP sheets. KSCE J. Civil Eng., 20: 1925-1935. DOI: $10.1007 / \mathrm{s} 12205-015-0790-5$

Ascione, F. and G. Mancusi, 2012. Curve adhesive joints. Composite Struct., 94: 2657-2664. DOI: 10.1016/j.compstruct.2012.03.024

Box, M.J., W.H. Swann and D. Davies, 1969. NonLinear Optimization Techniques. 1st Edn., Oliver and Boyd, Edinburgh, pp: 60.

Balsamo, A., A. Colombo, G. Manfredi, P. Negro and A. Prota, 2005. Seismic behavior of a full-scale RC frame repaired using CFRP laminates. Eng. Struct., 27: 769-780. DOI: 10.1016/j.engstruct.2005.01.002

Braga, F., R. Gigliotti and M. Laterza, 2006. Analytical stress-strain relationship for concrete confined by steel stirrups and/or FRP jackets. J. Struct. Eng., 132: 1402-1416. DOI: 10.1061/(ASCE)07339445(2006)132:9(1402)

Byrd, R.H., R.B. Schnabel and G.A. Shultz, 1987. A trust region algorithm for nonlinearly constrained optimization. SIAM J. Num. Analysis, 24: 1152-1170. DOI: $10.1137 / 0724076$
Chisari, C., 2015. Inverse techniques for model identification of masonry structures. PhD Thesis, University of Trieste.

Chisari, C., L. Macorini, C. Amadio and B.A. Izzuddin, 2015a. An inverse analysis procedure for material parameter identification of mortar joints in unreinforced masonry. Comput. Struct., 155: 97-105. DOI: 10.1016/j.compstruc.2015.02.008

Chisari, C., C. Bedon and C. Amadio, 2015b. Dynamic and static identification of base-isolated bridges using genetic algorithms. Eng. Struct., 102: 80-92. DOI: 10.1016/j.engstruct.2015.07.043

Choi, S.W., Y. Kim and H.S. Park, 2014. Multiobjective seismic retrofit method for using FRP jackets in shear-critical reinforced concrete frames. Composites Part B Eng., 56: 2017-216. DOI: 10.1016/j.compositesb.2013.08.049

D'Amato, M., F. Braga, R. Gigliotti, S. Kunnath and M. Laterza, 2012. A numerical general-purpose confinement model for non-linear analysis of $\mathrm{R} / \mathrm{C}$ members. Comput. Struct., 102-103: 64-75. DOI: 10.1016/j.compstruc.2012.03.007

D’Ambrisi, A., L. Feo and F. Focacci, 2013. Experimental and analytical investigation on bond between Carbon-FRCM materials and masonry. Composites Part B: Eng., 46: 15-20. DOI: 10.1016/j.compositesb.2012.10.018

Duong, K., D. Sheikh and F. Vecchio, 2007. Seismic behavior of shear-critical reinforced concrete frame: Experimental investigation. Struct. J., 104: 303-314.

EN1998-1, 2004. Design of structures for earthquake resistance-Part 1: General rules, seismic actions and rules for buildings. European Standard.

Fava, G., V. Carvelli and M.A. Pisani, 2016. Remarks on bond of GFRP rebars and concrete. Composites Part B: Eng., 93: 210-220. DOI: 10.1016/j.compositesb.2016.03.012

Gattesco, N., C. Amadio and C. Bedon, 2015. Experimental and numerical study on the shear behavior of stone masonry walls strengthened with GFRP reinforced mortar coating and steel-cord reinforced repointing. Eng. Struct., 90: 143-157. DOI: $10.1016 /$ j.engstruct.2015.02.024

Gattulli, V., G. Lampis, G. Marcari and A. Paolone, 2014. Simulations of FRP reinforcement in masonry panels and application to a historic facade. Eng. Struct., 75: 604-618.

DOI: 10.1016/j.engstruct.2014.06.023

Goldberg, D.E., 1989. Genetic Algorithms in Search, Optimization and Machine Learning. 13th Edn., Addison-Wesley Publishing Company, Reading, ISBN-10: 0201157675, pp: 412.

Gonilha, J.A., J.R. Correia and F.A. Branco, 2013. Dynamic response under pedestrian load of a GFRP-SFRSCC hybrid footbridge prototype: Experimental tests and numerical simulation. Composite Struct., 95: 453-463.

DOI: $10.1016 /$ j.compstruct.2012.07.029 
Lam, L. and J.G. Teng, 2003. Design-oriented stressstrain model for FRP-confined concrete in rectangular columns. J. Reinf. Plast Compos, 22: 1149-1184. DOI: 10.1177/0731684403035429

Le-Trung, K., K. Lee, J. Lee, D.H. Lee and S. Woo, 2010. Experimental study of RC beam-column joints strengthened using CFRP composites. J. Composi., Part B: Eng., 41: 76-85.

DOI: 10.1016/j.compositesb.2009.06.005

Mancusi, G., F. Ascione and M. Lamberti, 2014. Prebuckling behavior of composite beams: A mechanical innovative approach. Composite Struct., 117: 396-410.

DOI: 10.1016/j.compstruct.2014.06.041

Martinelli, E., F. Perri, C. Sguazzo and C. Faella, 2016. Cyclic shear-compression tests on masonry walls strengthened with alternative configurations of CFRP strips. Bull. Earthquake Eng., 14: 1695-1720. DOI: $10.1007 / \mathrm{s} 10518-016-9895-6$

Miettinen, K., 1999. Nonlinear Multiobjective Optimization. 1st Edn., Springer Science and Business Media, Boston.

Mishra, P.K., A.K. Pradhan and M.K. Pandit, 2016. Inter-laminar delamination analyses of Spar Wingskin Joints made with flat FRP composite laminates. Int. J. Adhesion Adhesives, 68: 19-29. DOI: 10.1016/j.ijadhadh.2016.02.001

Model Code, 2012. Final draft. fib 65, International Federation for Structural Concrete.

OpenSees, 2009. Open system for earthquake engineering simulation.

Panigrahi, S.K. and R.D. Rashmi, 2016. Study and analysis of damages in functionally graded adhesively bonded joints of laminated FRP composites: A critical review. Rev. Adhesion Adhesives, 4: 152-165. DOI: 10.7569/RAA.2016.097305

Parvin, A., S. Altay, C. Yalcin and O. Kaya, 2010. CFRP rehabilitation of concrete frame joints with inadequate shear and anchorage details. J. Composi. Construct., 14: 72-82.

DOI: 10.1061/(ASCE)CC.1943-5614.0000055
Poh'sie, G., C. Chisari, G. Rinaldin, M. Fragiacomo and C. Amadio et al., 2016. Application of a translational tuned mass damper designed by means of genetic algorithms on a multistory cross-laminated timber building. J. Struct. Eng., 142: E4015008. DOI: 10.1061/(ASCE)ST.1943-541X.0001342

Reyes, G., I. Hajirasouliha and K. Pilakoutas, 2010. Seismic behaviour of deficient RC frames strengthened with CFRP composites. Eng. Struct., 32: 3075-3085.

DOI: $10.1016 /$ j.engstruct.2010.05.026

Sarma, K. and H. Adeli, 1998. Cost optimization of concrete structures. J. Struct. Eng., 124: 570-578. DOI: 10.1061/(ASCE)0733-9445(1998)124:5(570)

Stadler, W., 1979. A survey of multicriteria optimization or the vector maximum problem, part I: 1776-1960. J. Optimizat. Theory Applic., 29: 1-52. DOI: 10.1007/BF00932634

Teng, J.G., J.F. Chen, S.T. Smith and L. Lam, 2002. FRP-Strengthened RC Structures. Wiley, New York, ISBN-10: 0471487066, pp: 245.

Yang, X., Y. Bai, F.J. Luo, X.L. Zhao and F. Ding, 2016. Dynamic and fatigue performances of a large-scale space frame assembled using pultruded GFRP composites. Composite Struct., 138: 227-236. DOI: 10.1016/j.compstruct.2015.11.064

Yazdanbakhsh, A., L.C. Bank and C. Chen, 2016. Use of recycled FRP reinforcing bar in concrete as coarse aggregate and its impact on the mechanical properties of concrete. Construct. Build. Mater., 121: 278-284. DOI: 10.1016/j.conbuildmat.2016.05.165

Zhu, J., X. Wang, Z. Xu and C. Weng, 2011. Experimental study on seismic behavior of $\mathrm{RC}$ frames strengthened with CFRP sheets. Composite Struct., 93: 1595-1603.

DOI: 10.1016/j.compstruct.2011.01.007

Zou, X.K., J.G. Teng, L. De Lorenzis and S.H. Xia, 2007. Optimal performance-based design of FRP jackets for seismic retrofit of reinforced concrete frames. Composi. Part B: Eng., 38: 584-597. DOI: 10.1016/j.compositesb.2006.07.016 